\title{
O planejamento das políticas educativas no Brasil e seus desafios atuais
}

\author{
Eliza Bartolozzi Ferreira* \\ Marília Fonseca*
}

\section{Resumo}

O presente texto tem por objetivo apresentar reflexôes preliminares procedentes de uma pesquisa interinstitucional focada no Plano de Açóes Articuladas - PAR. Os procedimentos metodológicos adotados foram os seguintes: análise bibliográfica sobre planejamento no Brasil; análise dos documentos legais e normativos de criação e implantação do PAR; entrevistas com os técnicos responsáveis pelo planejamento dos municípios participantes da amostra. Com o PAR, o governo Lula inaugurou uma forma de planejamento sistêmico por meio da adoção de um mecanismo que instaura um regime de colaboração entre os entes federativos. A proposta do Ministério da Educação foi fortalecer o regime de colaboração, comprometendo-se em ir ao encontro dos entes federados para conhecer a sua realidade e assumir o compromisso de assisti-los técnica e financeiramente. Esta pesquisa evidenciou a tradicional dificuldade de equilíbrio entre as políticas locais e a central, sobretudo atualmente com as novas regulaçóes introduzidas pelas reformas educativas implantadas desde a década de 1990. A gestão pública tornou-se mais técnica, oferecendo soluçôes racionais, supostamente neutras, para o enfrentamento dos problemas econômicos e sociais. Além disso, as entrevistas revelaram as dificuldades das equipes em prever as açóes futuras, o que constitui a base de um bom planejamento, com o agravante da baixa participação dos segmentos da comunidade e da escola devido à falta de informaçôes e/ou às injunçôes decorrentes das relaçóes de poder local que inibem o posicionamento autônomo dos sujeitos.

Palavras-chave: Planejamento educacional. Centralização. Descentralização.

Doutora em Educação pela Universidade Federal de Minas Gerais (UFMG). Professora do Programa de Pós-Graduação em Educação da Universidade Federal do Espírito Santo e coordenadora do Núcleo de Estudos e Pesquisas em Políticas Educacionais. Secretária adjunta da Associação Nacional de Pós-Graduação e Pesquisa em Educaçáo (ANPED).

** Doutora em Ciências daEducação e pesquisadora associada da Faculdade de Educação da Universidade de Brasília (UnB). 


\section{Introdução}

O planejamento é uma das estratégias utilizadas para imprimir racionalidade ao papel do Estado e institucionalizar "as regras do jogo" na administração das políticas governamentais. ${ }^{1}$ Durante o Século XX, tornou-se comum estabelecer uma estreita conexáo entre o plano e a institucionalização da centralização administrativa. Segundo esse postulado, Estado e planejamento seriam sinônimos de autocracia. Interpretaçóes diferenciadas podem advir dessa relação, dependendo da orientação política do Estado. Uma delas estabelece conexão entre descentralização e democracia, admitindo-se que o planejamento pode ser o instrumento por meio do qual se estabelecem políticas descentralizadas, dando a ideia do Estado como a entidade na qual a sociedade inteira se representa.

Em tal contexto, o planejamento transcorre como uma atividade técnica de organizar as açóes para atender as necessidades essenciais da populaçáo e prover os países de uma estruturaçáo econômica e social. Convivendo com essa dimensão técnica, há no planejamento uma decisão política de normatização e de controle social. $\mathrm{Na}$ dimensão política, o planejamento tem sido objeto de estudo de autores que buscam compreendêlo em suas diferentes funçóes. Entre os formatos estudados por Sartori (1994), o planejamento total, também conhecido como planejamento central ou totalitário, é o planejamento de um Estado que é dono absoluto das "regras do jogo", ou seja, é o único a tomar decisóes sobre as diretrizes políticas que regeráo a sociedade. Em síntese, o planejamento total é um planejamento que serve à "soberania dos objetivos". O formato que o autor denomina limitado é aquele que admite compatibilidade entre democracia e planejamento. De qualquer modo, o planejamento democrático vive uma profunda contradição com o avanço da tecnocracia, caso em que a opiniáo do especialista adquire um peso bem maior que o voto do eleitor. Numa posição similar, Bobbio (1986) destaca que a democracia sustenta-se sobre a hipótese de que todos podem decidir a respeito de tudo. A tecnocracia, ao contrário, pretende que sejam convocados para decidir apenas aqueles poucos que detêm conhecimentos específicos.

A caracterização de planejamento como categoria histórica do processo de controle social, estudada por Pereira (1978), conduz à compreensão de que a implantaçáo da planificaçáo no desenvolvimento do sistema 
capitalista é resultado de um processo político que, por seu turno, exprime o embate de interesses de classes divergentes. A defesa de uma modalidade de planejamento exprime, portanto, posiçóes políticas em competição no interior dos sistemas centrais e periféricos. Em meio às tensóes em que se encontra o aparelho estatal o planejamento funciona como elemento racional para organizar a política do Estado que compreende condições e objetivos econômicos, sociais, políticos e administrativos, ainda que em graus variáveis. Em linhas gerais, a organização racional do Estado é realizada a partir de algumas hipóteses sobre a realidade, sendo o planejamento a forma concreta de definição das ações e dos meios para seu alcance, quando um país pretende transformar ou consolidar determinadas estruturas sociais e econômicas.

O planejamento estatal, portanto, traz em si uma carga de controle social e, conforme assevera Ianni (1995), não deixa de expressar a ideologia hegemônica do Estado. Por essa razão, as estruturas de poder são determinantes para configurar o caráter do planejamento, pois "o planejamento é um processo que começa e termina no âmbito das relaçóes e estruturas de poder" (IANNI, 1995, p. 309). O desenvolvimento da democracia passa a ser imprescindível para que o processo de planejamento seja assegurado em sua complexidade econômica e social. Isto significa a possibilidade de adicionar à tecnocracia estatal as discussóes e expectativas da sociedade civil organizada para corresponder às suas demandas de emancipação política e econômica.

\section{O planejamento da educação no Brasil: educadores versus tecnocratas}

O planejamento firmou-se como prática desde a década de 1920, sendo visto como um instrumento de reconstrução de naçóes afetadas pela Primeira Guerra Mundial e pela crise de 1929. No período que se seguiu à Segunda Guerra o planejamento consolidou-se mediante a criação de novas entidades internacionais de caráter econômico e financeiro (a exemplo do Fundo Monetário Internacional (FMI) e do Grupo Banco Mundial), cuja finalidade era elaborar planos para reorganizar a economia dos países europeus afetados pela guerra. Nos anos de 1950, a ação dessas organizaçóes internacionais estendeu-se para outras regióes do "Terceiro Mundo" na forma de "cooperação para o desenvolvimento". A cooperaçáo se concretizava, 
até os anos de 1960, notadamente por meio de empréstimos financeiros destinados à execução de projetos de infraestrutura econômica. A partir daí, o setor social passou a ser beneficiário desses empréstimos.

Como observou Scaff (2007), o processo de cooperação econômica contribuiu para a consolidação do planejamento estatal dos países receptores - entre eles o Brasil. Em países da América Latina esse papel coube à Comissão Econômica para a América Latina (CEPAL), cujo objetivo era a aceleração do desenvolvimento econômico da região. $\mathrm{O}$ planejamento educacional, por sua vez, teve como fonte orientadora a Organização das Nações Unidas para a educação, a ciência e a cultura (UNESCO) (órgão ligado à Organização das Nações Unidas - ONU para o desenvolvimento da educação), com o suporte de sua entidade afiliada, o Instituto Internacional para o Planejamento da Educação (IIPE). Nessa área, a UNESCO foi promotora de eventos de âmbito mundial, como a Conferência Internacional para o Planejamento da Educação, realizada em Paris, em 1968, e o Congresso Internacional de Planejamento e Gestão do Desenvolvimento Educacional, que teve lugar no México, em 1990.

Diante de tal evidência é legítimo supor que os países, ao acatarem a orientação externa para a construção dos planos e projetos, internalizam também os valores, objetivos e métodos implícitos aos modelos internacionais de planificação. Concorrem para isto as condiçóes políticas impostas nas cláusulas dos empréstimos concedidos por agências financiadoras, como o Banco Mundial. A UNESCO, por sua vez, não atua como órgão de financiamento (não obstante ser um captador financeiro), mas detém o poder de influenciar políticas educacionais ao reunir os países em torno de eventos de larga escala. Uma questão a ser considerada é que a intensidade da influência internacional tem a ver com a forma - compartilhada ou autonômica - com que os governos interagem com o campo internacional, e isto certamente tem a ver com a própria orientação político-ideológica de cada governo nacional.

O olhar retrospectivo sobre o planejamento brasileiro abre espaço para compreender a sua função na dinâmica institucional do Estado. Os diferentes estilos políticos adotados deram o tom das relaçóes entre o Estado e as corporaçóes internacionais, e, internamente, entre as relaçóes da União com os demais entes federados. No decorrer do período republicano, o Estado oscilou entre diferentes direçôes políticas: em certas fases, 
orientou-se pelo conservadorismo econômico; em outras, aderiu ao liberaldesenvolvimentismo ou ao neoliberalismo; privilegiou políticas centralizadas e descentralizadas. $\mathrm{O}$ processo de planejamento adotou diferentes estilos que correspondiam a diferentes funçóes e incorporavam variáveis políticas, econômicas e sociais. De acordo com esses formatos foram adotadas diferentes nomenclaturas, tais com o planejamento tradicional, estratégico, situacional, participativo.

Para Baia Horta (1982), a ideia de planejar a educação brasileira vinha amadurecendo desde o início da década de 1930 pela atuação dos educadores conhecidos como pioneiros ou renovadores. A IV Conferência Nacional de Educação, promovida em 1931 pela Associação Brasileira de Educação - ABE, resultou numa proposta conhecida como Manifesto dos Pioneiros, cujo objetivo era fundamentar um futuro plano nacional de educação. A Constituição de 1934 assegurou ao recém-criado Conselho Nacional de Educação a competência para elaborar o futuro plano e também participar da distribuição dos fundos especiais.

Com a instauração do Estado Novo, o planejamento deu o tom da aspiração desenvolvimentista do governo, cuja ideia-força residia no fortalecimento do Estado com base em um projeto industrial de larga escala. Mais do que um plano, a proposta educacional dava suporte às pretensóes econômicas do governo. Com a forte influência dos militares e dos católicos novas propostas foram agregadas a um novo plano de educação que seria apresentado ao Congresso em 1937, o qual tampouco foi aprovado devido a uma remanescente resistência de segmentos da sociedade, especialmente dos educadores. Na sequência, prevaleceu a orientação doutrinária e os objetivos pragmáticos do Estado Novo, organizando o ensino básico por ramos profissionais que correspondiam à divisão econômico-social do trabalho e das classes sociais; uma educação diferenciada para a elite, para a mulher e para aqueles que comporiam o grande exército de trabalhadores tendo em vista dar suporte ao projeto industrial do governo.

A política desenvolvimentista do governo Kubitschek, eleito para o período 1956-1961, voltou a privilegiar o planejamento estatal, concretizado pelo programa de metas, que deu suporte à nova linha desenvolvimentista adotada pelo governo. A educação foi incorporada ao plano estatal com o propósito de preparar pessoal técnico para a implantação das indústrias de base. Nesse período, a vinculação entre educação e economia ganhou 
destaque internacional pela emergência da teoria do capital humano e do enfoque de mão de obra (man power approach). Tal enfoque é um método de planejamento que consiste em determinar as metas de um plano de educaçáo com base na demanda do mercado de trabalho, especialmente quanto ao perfil e ao quantitativo de trabalhadores. Articula-se com a teoria do capital humano, segundo a qual o desenvolvimento dos recursos humanos pelo sistema educacional é um requisito essencial para o crescimento econômico dos países. A educação deveria, portanto, produzir competências técnicas para o emprego, de forma a agregar valor aos recursos humanos no mercado.

O período de 1956 a 1963, que abarcou os governos democráticos de Kubitschek a Goulart, foi profícuo para a mobilização dos educadores que voltaram a debater as suas ideias em fóruns nacionais. Segundo Fonseca (2009), os debates concentravam-se nos compromissos assumidos nas conferências internacionais, notadamente as que foram realizadas em Punta del Leste e Santiago do Chile, em 1961 e 1962. Estas últimas contaram com o patrocínio da Organização dos Estados Americanos (OEA) e de um programa de cooperação técnica e econômica do governo norte-americano: "Aliança para o progresso". Além do aspecto doutrinário que recomendava a integração da educação ao desenvolvimento econômico e social, as conferências estabeleceram metas decenais para a educação na América Latina.

A orientação dos fóruns internacionais sofreu resistências por parte dos educadores e de intelectuais reunidos no Instituto Superior de Estudos Brasileiros (ISEB), especialmente com respeito ao enfoque econômico defendido nos fóruns. A década de 1960 representou um marco na educação brasileira, particularmente pela promulgação da primeira Lei de Diretrizes e Bases da Educação (1961) e também pela implementação dos primeiros planos educacionais (BRASIL, 1962, 1963). Embora os planos guardassem uma dimensão eminentemente quantitativa (privilegiando o estabelecimento de metas), a orientação de Anísio Teixeira ainda espelhava a resistência nacional. Ao adaptar as metas ao contexto brasileiro o educador se contrapôs ao consenso internacional que previa metas comuns para a América Latina.

Nos governos militares o planejamento da educação passou a compor os planos nacionais de desenvolvimento. A educação absorveu, assim, a ideologia fomentada pelos tecnoburocratas, cuja influência seria cada vez mais fortalecida nos governos subsequentes. Adotou-se o viés economicista 
dos fóruns internacionais, culminando com a obrigatoriedade da educação profissional, estabelecida pela Lei n⿳0 5.692/1971. O poder da tecnocracia nos anos de 1970 chegou a merecer a crítica de Bresser Pereira (1977). Segundo ele, no quadro de uma formação social ainda dominantemente capitalista "o planejamento seria uma forma de a tecnoburocracia estatal aumentar o seu poder no seio do Estado, por meio de uma rede extensa e intrincada de planos e planejadores. A crença na superioridade do planejamento seria, pois, mais uma ilusão tecnoburocrática do que uma realidade" (BRESSER PEREIRA, 1977, p. 116).

No começo da década de 1980, a mobilização social fortaleceu-se pela ação de fóruns científicos e acadêmicos, como a Associação Nacional de Pesquisa em Educação (ANPED) e a Sociedade Brasileira para o Progresso da Ciência (SBPC). O III Plano Setorial do Ministério da Educação (MEC) para o período 1980-1985 (BRASIL, 1980) buscou espelhar a ambiência democrática que marcou o final do governo militar. Sua elaboração deu-se por um processo de planejamento participativo, congregando entidades acadêmicas e representativas do setor educacional, além de pessoal técnico das administraçóes estaduais e municipais. Devido à descontinuidade administrativa que marcou esse período, a proposta participativa de planejamento foi descartada com menos de um ano de execução. Nesse período, órgãos eram criados e desfeitos, as políticas eram substituídas segundo o estilo de cada gestão.

Em meados da década, o planejamento educacional passou a sofrer influência direta da cooperação do Banco Mundial. De acordo com o estudo de Fonseca (2009), por meio de uma série de acordos com o MEC para o financiamento da Educação Básica, as diretrizes políticas fixadas pelo Banco passaram a compor os planos educacionais (BRASIL, 1980, 1986). Segundo o estabelecido nos projetos em execução (Monhangara, Edurural e futuro Projeto Nordeste, executado nos anos de 1990) previa-se "fornecer" aos estados da região modelos de planejamento para as escolas; diversificar o atendimento educacional, adequando conteúdos, métodos e organização às especificidades de cada grupo ou "clientela"; dar atendimento especial às periferias urbanas e zonas rurais mediante um ciclo de educação inicial e preparaçáo para o trabalho antecipado; preparar planejadores e gestores da educação nos níveis federal, estadual e municipal, adequando os "processos gerenciais e organizacionais, buscando agilizar a utilização dos insumos e 
produtos do setor e avaliação dos seus resultados" (BRASIL, 1986, p. 21); definir novas fontes de financiamento estaduais, municipais e federais, além de elaborar estudos sobre custo aluno, avaliaçóes de impacto, capacitaçáo técnico-pedagógica e gerencial de profissionais da educação.

A década de 1990 sofreu com a descontinuidade política, motivada pela destituição de Collor de Mello e sua substituição por um governo transitório. A política educacional de Murílio Hingel, Ministro da Educação à época, buscou dar outro contorno às relaçóes federativas, conclamando a participação geral em torno do "Acordo Nacional de Educação". Ao mesmo tempo, a Conferência Internacional de Jomtien, realizada em 1990 na Tailândia, sob a coordenação de organismos internacionais (UNESCO, Programa das Naçóes Unidas para o Desenvolvimento (PNUD), Fundo das Naçóes Unidas para a Infância (UNICEF) e Banco Mundial), resultou na "Declaração Mundial sobre Educação para Todos", a qual passou a orientar as políticas educativas. Por sua vez, o plano brasileiro de "Educação Para Todos", elaborado no final do mandato de Hingel, incorporou as orientaçóes doutrinárias e as metas quantitativas dos organismos internacionais, entre elas, a prioridade à ampliação do ensino fundamental, em detrimento do ensino médio, e a implantação de um amplo sistema de avaliação da Educação Básica com a finalidade de aferir a aprendizagem dos alunos do ensino fundamental (BRASIL, 1993). No decorrer da década, sob o governo de Fernando Henrique Cardoso, o enfoque internacional foi confirmado pela prioridade ao ensino fundamental (marcada pelo Fundo de Manutenção e Desenvolvimento do Ensino Fundamental e de Valorização do Magistério (FUNDEF) e a institucionalização do Sistema de Avaliação da Educação Básica (SAEB).

Percebe-se, portanto, que, na década de 1990, o planejamento educacional brasileiro oscilou entre a construção de uma proposta nacional e as demandas oriundas do campo internacional. Em meados da década ocorria uma ampla mobilização social em torno da elaboração do Plano Nacional de Educação (PNE), com a participação de amplos segmentos da sociedade civil organizada em fóruns nacionais. $\mathrm{O}$ texto base do PNE incorporou propostas oriundas dos congressos nacionais de educação (CONED), assim como outras surgidas no debate legislativo com a participação de diferentes entidades civis. A mobilização social logrou algumas conquistas no tocante à afirmação da gestão democrática, inclusive abrindo oportunidade para a 
construção de planos estaduais e municipais e para o estabelecimento de metas de longo prazo.

Desde a sua aprovação em 2001, o PNE recebeu reiteradas críticas quanto ao seu real alcance para o desenvolvimento da educação, decorrente, sobretudo, da desatenção dos governos que se seguiram quanto à execução das metas. Segundo análise de Sousa (2010), a Lei no 10.172/2001, que instituiu o PNE, determinou no seu artigo $2^{\circ}$ aos estados, ao Distrito Federal e aos municípios a elaboração de planos decenais correspondentes e em sintonia com o plano nacional. Determinou ainda, no seu artigo $3^{\circ}$, que "A União, em articulação com os estados, o Distrito Federal, os municípios e a sociedade civil, procederá a avaliaçóes periódicas da execução do Plano Nacional de Educação" (SOUSA, 2010, s/p). Para cumprir a citada lei, o Ministério da Educação deveria ter, desde a sanção da lei, implantado uma estrutura capaz de atender a essas demandas. Somente em dezembro de 2005, o MEC criou uma gerência, na estrutura da Secretaria de Educação Básica (SEB), denominada "Programa de Acompanhamento e Avaliação do PNE e dos Planos Decenais Correspondentes”. Com uma estrutura de pessoal deficitária, o programa realizou apenas três seminários para a formaçáo de técnicos e gestores das secretarias estaduais e municipais de educação com o objetivo de acompanhar as metas do PNE e elaborar, acompanhar e avaliar seus respectivos planos, promovendo ainda outras açóes de natureza técnica e pedagógica. No momento de expirar a vigência do PNE muitas de suas metas não foram alcançadas no âmbito da administração federal e dos governos estaduais e municipais e praticamente a metade dos municípios brasileiros conta com plano municipal de educação, o que atesta as críticas sobre o descumprimento do plano.

\section{Planejamento educacional em tempos de globalização}

$\mathrm{Na}$ década de 1990, a "administração racional ou gerencial" erigiuse como pilar da reorganizaçáo sofrida pelos Estados em função do novo modelo econômico que se estabeleceu em âmbito global. Essa reorganização é explicada por Bruno (1999) como uma estrutura sistêmica para a qual o planeta é uma unidade econômica única, sem fronteiras. Dessa forma, o processo econômico náo se encontra mais definido nem controlado por qualquer país em particular, mas por uma rede de grupos econômicos e/ou 
por agências reguladoras internacionais que se configuram como centros de poder econômico e político.

Entre essas, pode-se citar o Fundo Monetário Internacional, Banco Mundial, Organização Mundial do Comércio, Grupo dos Países mais Ricos do Mundo (G7), Bancos Centrais, Empresas Globais e, ainda, conglomerados financeiros e de países ou regiôes ricas, tais como Estados Unidos, Japão e União Europeia.

Esse processo impôs inúmeros desafios para as políticas de cada país em particular e, dentre essas, para as políticas sociais. A educação, por exemplo, foi afetada, tendo sido impelida a executar reformas capazes de modificar finalidades, valores e práticas educativas. A gestão educacional - e, nela, especificamente a gestão escolar - passou a orientar-se pelo modo gerencial que foi, sem dúvida, uma estratégia para levar as instituiçóes escolares a trilharem modelos técnicos de planejamento que tomam o mercado como exemplo de eficiência. Sob denominaçóes distintas, essa nova modalidade de planejamento escolar fora experimentada, até mesmo antes da década de 1990, em diversos países da Europa Ocidental, Leste Europeu e da América do Norte.

No Brasil, o planejamento estatal teve grande destaque nos governos militares, mas sua institucionalização se deu no governo Collor de Mello (1990-1992) devido ao dispositivo constitucional que instaurou o Planejamento Plurianual, determinando ao Executivo a elaboraçáo de planos para o estabelecimento de metas, diretrizes e objetivos da administração pública. No governo de Fernando Henrique Cardoso (1995-2002) o planejamento assumiu importância decisiva na organização das açóes do Estado brasileiro. Em atendimento aos reclamos da nova ordem neoliberal que se instalara mundialmente, o governo deu um novo formato à estrutura e à gestão pública por meio da "Reforma do Aparelho do Estado." Na condição de ministro da Administração e Reforma do Estado, Bresser Pereira implantou uma peculiar modalidade de descentralização por meio da qual foram transferidas funçóes da burocracia central para estados e municípios e para as denominadas organizaçóes sociais, ditas públicas não estatais (BRASIL, 1995). Para evitar qualquer risco de enfraquecimento institucional do Estado e, dessa forma, garantir a "governança" foram adotadas medidas controladoras, entre as quais a Lei de Responsabilidade Fiscal e as restriçóes orçamentárias dela decorrentes. 
De acordo com Ferreira (2007), a gestão pública tornou-se mais técnica, oferecendo soluçóes racionais, supostamente neutras, para o enfrentamento dos problemas econômicos e sociais. $\mathrm{O}$ objetivo era imprimir eficiência ao setor público por meio da consolidação de um Estado gerencial, entendido como uma instituição político-regulatória que buscaria corresponsabilizar outros setores/instituiçóes em favor do desenvolvimento social do país. O Estado gerencial é aquele que pretende desenvolver uma gestão econômica eficiente e que, sem estar no mundo produtivo, pauta-se pela sua organização, portanto, incorpora a ideologia do mercado. Busca avaliar os resultados das políticas públicas que chegam aos cidadãos por meio das agências reguladoras nos âmbitos federal e estadual, baseadas no princípio da autonomia e da manutenção de relaçóes equilibradas com o Governo, os usuários e as concessionárias dos serviços públicos.

O planejamento estratégico, em sua modalidade gerencial, foi o instrumento escolhido para organizar as açóes de forma racional e descentralizada. Os argumentos em favor da descentralização afirmavam a sua característica inovadora capaz de imprimir autonomia e transferência de poder das autoridades superiores para as autoridades locais. Do lado mais crítico, argumentava-se que a propalada "descentralização" apenas transferia para as administraçóes locais as responsabilidades operativas, antes atribuídas ao poder central. A dita "organização racional do sistema" se resumiria à adoção de instrumental técnico para que o sistema alcançasse maior eficiência. Estimulou-se a aquisição, pelos agentes escolares, de atributos gerenciais que privilegiassem a gestão física e financeira da escola. Nessa trilha, as instituiçóes públicas experimentaram modalidades de avaliação para medir o desempenho escolar; o rendimento dos alunos passou a ser aferido por testes padronizados; professores foram levados a participar de atividades que náo se limitavam à sala de aula, mas que interferiam na organização da escola como um todo.

Faziam parte da política descentralizadora os programas "dinheiro direto na escola”, tais como o Programa Dinheiro Direto na Escola (PDDE) e o Plano de Desenvolvimento da Escola (PDE/escola), que integrava o programa Fundo de Fortalecimento da Escola - Fundescola, em fase de execução desde 1998, nas regióes Norte, Nordeste e Centro-Oeste. O Fundescola foi objeto de análise no âmbito de uma pesquisa realizada em diferentes estados brasileiros (FONSECA; TOSCHI; OLIVEIRA, 2004). ${ }^{2}$ 
Os resultados mostraram que o PDE seguia a orientação de uma escola funcional, centrada na definição de um padrão de referência pré-determinado de insumos necessários para melhorar o funcionamento das escolas. Sob essa orientação, a gestão educacional incorporou um sentido peculiar em que a visão estratégica do programa incidia sobre a organização racional, conforme as normas e as orientaçôes previamente estabelecidas nas cláusulas do Fundescola. A proposta centrava-se na aquisição, pelos agentes escolares, de "atributos gerenciais", "ferramentas de gestão" e "treinamento em serviço". Com essa preparação, visava-se capacitar os agentes para o desenvolvimento de produtos e estratégias voltados à superação dos principais problemas que afetam o "sistema educacional"; o adensamento das intervençóes em áreas prioritárias, potencializando os resultados; a montagem de estruturas de suporte local para a implantação das estratégias. As mudanças propostas no PDE/escola incidiam sobre a estrutura do sistema educativo, sendo prioritariamente movidas por imperativos próprios do mercado, como a busca de racionalização de gastos e eficiência operacional. É a ação orientada para resultados ou produtos.

Ao aderirem ao programa, estados, municípios e escolas absorveram a metodologia de planejamento estratégico, considerado base para a implantação do gerenciamento racional. No âmbito do PDE/escola, por exemplo, adotou-se um modelo de gestão de recursos que se fazia por intermédio de uma entidade de "direito privado" denominada Associação de Apoio à Escola, legalmente constituída para gerir os recursos repassados diretamente à escola. Cabia, porém, ao "diretor/líder/gerente" adquirir competência para buscar outras fontes de recursos para a escola, mediante convênios, acordos e contratos com entidades públicas e privadas, nacionais ou internacionais. Era uma forma de adaptar a gestáo escolar ao modelo organizacional do mercado, tal como previa o enfoque racional de administração, implantado pelo PDE.

No governo Lula da Silva (2003-2010) foi criado o Plano de Açóes Articuladas (PAR) com o objetivo de viabilizar a autonomia institucional e a qualidade da educação brasileira. Pode-se afirmar que o PAR inaugura uma forma de planejamento sistêmico, por meio da adoção de um mecanismo que instaura um regime de colaboração entre os entes federativos.

Com a finalidade de aprofundar a reflexão acadêmica sobre os desafios do planejamento escolar, a pesquisa que dá origem ao presente 
texto busca apreender se a condução do PAR segue a trilha da hegemonia e centralidade do Estado ou se constitui um meio para dar voz à sociedade civil na condução da gestão pública. Parte-se do ponto de vista de que a ação educativa, em tese, não seria mero reflexo dos planos oficiais tendo em vista que as metas de longo prazo nem sempre se sustentam ao longo do tempo, o que demanda modificaçóes e adaptaçóes. Concorrem para isto as demandas oriundas de setores reivindicativos da sociedade, as quais são incorporadas em períodos de maior mobilização social. Leva-se, ademais, em conta que as mudanças desencadeadas com a promulgação da Constituição Federal de 1988 deram espaço mais amplo à autodeterminação dos entes federados (estados e municípios).

Não se pode perder de vista, porém, que a União conta com expressivo poder de barganha, por via de um modelo centralizado de financiamento. $\mathrm{O}$ assunto foi foco de análises e debates na reunião do Grupo de Trabalho (GT 5) da ANPEd, realizada em Curitiba (CAMINI 2010; FARENZENA, 2010). As autoras deixaram patente que a centralização da receita na União no Fundo Nacional de Desenvolvimento da Educação (FNDE) pode aumentar mais o poder de barganha do Governo Federal, especialmente por meio do aumento de recursos disponíveis para as transferências voluntárias. O estudo de Cruz (2010) acrescentou outras informaçóes sobre a centralização financeira no FNDE. Criado em 1968, com o objetivo de financiar ações suplementares ao ensino fundamental, o Fundo ampliou paulatinamente seu raio de ação para todas as etapas da Educação Básica. Em 2006, foi responsável pela execução de 78\% (CRUZ, 2010) dos recursos do MEC para a Educação Básica. Resta indagar se a centralização dos recursos pode facilitar a primazia técnica do FNDE nos assuntos pedagógicos de responsabilidade do MEC e dos sistemas educativos.

\section{O Planejamento educacional no governo de Lula: o PAR como estratégia para consolidar o regime de colaboração entre os entes federados}

Visto do ângulo político o planejamento está intimamente ligado à própria estrutura do regime federativo e das condiçóes por ele impostas no que diz respeito ao movimento de centralização-descentralização administrativa e financeira. A tese de doutorado de Martins (2009), 
defendida no programa de Pós-Graduação em Educação da Universidade de Brasília, observando as relaçóes entre o poder central e os entes federados brasileiros, mostra que estas não tiveram uma evoluçáo contínua e linear ao longo da história republicana, mas foram permeadas por momentos de maior ou menor centralização, compreendida como concentração de poder político e financeiro no governo central (União) ou de maior distensão em relaçáo aos estados e municípios. Tanto no período do Império como no da República, até a redemocratização consolidada com a Constituição Cidadá de 1988, considerou-se a questão da autonomia municipal como um problema provincial/estadual e não federativo. Não havia autonomia para a organização da esfera: era comum que a esfera estadual aprovasse uma lei orgânica para o conjunto de seus municípios. Somente com a Carta de 1988 os municípios foram guindados a entes federativos com a outorga de elementos constitutivos do equilíbrio federativo e, portanto, da autonomia municipal (autogoverno, autolegislação, autoadministração).

$\mathrm{O}$ equilíbrio federativo entrou em pauta na discussão sobre o financiamento da educação por meio do FUNDEF. O mecanismo que expressava este compromisso do poder central era a complementaçáo da União, cujo parâmetro se estabelecia em função do valor mínimo a ser despendido por aluno em cada ano. Com esse mecanismo, instituiu-se o regime de colaboração em que a União participaria do esforço federativo para financiar a educação. Segundo Martins (2009), a proposta colaborativa debilitou-se pela entrada em vigor do Fundo de Estabilização Fiscal que reduzia a obrigação da União de aplicaçáo de recursos resultantes da receita de impostos para o patamar real de 14,4\%. Este mecanismo, somado à Desvinculação das Receitas da União (DRU), instituída em 2000, inibiu o cumprimento do papel da União. O descumprimento de dispositivo constitucional acerca da aplicaçáo de recursos da União no ensino fundamental via Fundef durou até a primeira gestão de Lula. Ainda que a ideia-força desse governo fosse a inclusão social, o ajuste fiscal continuou a conformar as açóes do governo com a fixação de metas de inflação, responsabilidade fiscal e superávits primários. $\mathrm{O}$ fato foi recorrentemente denunciado por entidades representativas (entre elas o Conselho Nacional de Educação (CNE) que reclamavam a necessidade de fazer vigorar o regime de colaboração, incitando o aumento da participação da União via adoção de um fundo único e abrangente a todas as etapas do ensino básico - tal qual fora previsto no Plano Nacional de Educação. 
Com a eleição do presidente Lula implantou-se o Fundo de Manutenção e Desenvolvimento da Educação Básica e de Valorização dos Profissionais da Educação (FUNDEB). O novo fundo foi construído a partir da instituição de uma instância de negociação federativa: a Comissão Intergovernamental de Financiamento para a Educação de Qualidade, composta por representantes dos três entes federados, além da participação do MEC e de entidades representativas da sociedade, como o Conselho Nacional dos Secretários de Educação (CONSED) e a União dos Dirigentes Municipais de Educação (UNDIME). No campo da educação, a questão federativa ganhara espaço, segundo Martins (2009, 2010), nos debates sobre a tramitação legislativa do FUNDEB. Os atores que representavam cada esfera de governo e os movimentos sociais colocavam em pauta a questão do equilíbrio federativo, especificamente no que se referia à direção dos fluxos de recursos redistribuídos (se de estado para o município ou de município para o estado), na definição de quais matrículas e quais impostos comporiam a cesta do fundo. Para Martins (2009, 2010), uma das contribuições mais importantes do processo de construção do FUNDEB foi a experiência de participação social que se deu na Câmara dos Deputados. O protagonismo dos movimentos sociais, organizados em rede, com formulação, acompanhamento e combinação de pressão política e argumentos técnicos, reverteu aspectos significativos (como a proposta de exclusão das creches) e contribuiu para o novo desenho de complementação da União. Para tanto, foi fundamental o trabalho de representantes do setor educacional no Executivo e no Legislativo, com alto grau de coesão, inclusive suplantando, em algumas questóes, as diferenças político-partidárias.

Em 2007 o governo Lula lançou o Plano de Desenvolvimento da Educação (PDE), constituído por 30 metas para enfrentar os desafios da qualidade educacional, das quais 17 se referem à Educação Básica. O PDE propóe-se a promover a melhoria do Índice de Desenvolvimento da Educação Básica (IDEB) dos entes federativos. De acordo com o documento oficial (BRASIL, 2007), o PDE é um plano executivo, constituído por programas divididos em quatro eixos norteadores: Educação Básica, Educação Superior, educação profissional e alfabetização. O PDE tem a finalidade de, complementarmente ao FUNDEB, consolidar o regime de colaboração, proporcionar maior autonomia aos entes federados, enfim, contribuir para a equalização da oferta educacional e para a sua melhor 
qualidade. O regime de colaboração pressupóe a participação dos governos subnacionais e a responsabilidade dos entes no cumprimento de 28 diretrizes. Em 2007, os municípios que firmaram convênios receberam R \$ 432,5 milhôes da União (BRASIL, 2007). Para a consecução desse compromisso, os governos subnacionais elaboraram os planos de açóes articuladas, os quais, segundo o MEC, substituem os convênios temporários e evitam o risco da tradicional descontinuidade das políticas educacionais.

Um dos princípios estabelecidos é o da necessária articulação entre a Uniâo, estados, Distrito Federal e os municípios para a garantia do direito à educação no país. Portanto, a colaboração entre os entes federativos é fundamental para a execução do PDE. Segundo o documento oficial, isso significa compartilhar competências políticas, técnicas e financeiras para executar os programas e açôes. "A Uniẫo passou, com o PDE, a assumir mais compromissos perante os estados, os municípios e o Distrito Federal, para, respeitando os princípios federativos, dar unidade ao desenvolvimento da educação e corrigir as distorçôes que geram desigualdades" (BRASIL, 2007).

A intenção do Ministério da Educação é integrar um conjunto de programas para dar organicidade ao sistema nacional de educação, mobilizando toda a sociedade em prol da melhoria da qualidade da educação. Ao considerar os quatro eixos norteadores, Educação Básica, Educação Superior, educação profissional e alfabetização, o PDE adota a chamada "perspectiva sistêmica da educação", isto é, vê o ensino fundamental relacionado ao ensino superior, o incentivo à pesquisa influindo no ensino médio, o transporte escolar articulado com a remuneração dos professores. Dessa forma, o PDE é um plano estrutural de longo prazo e pressupóe a superação da tradicional fragmentação das políticas educacionais e o diálogo entre os entes federativos.

Com o objetivo de identificar os problemas que afetam a qualidade da educação brasileira, o PDE promoveu uma alteração na avaliação nacional da Educação Básica com a criação da Prova Brasil. A partir disso, o MEC buscou cruzar os resultados de desempenho escolar (Prova Brasil) e os resultados de rendimento escolar (fluxo apurado pelo censo escolar) em um único indicador de qualidade: o Índice de Desenvolvimento da Educação Básica (IDEB). O IDEB foi elaborado pelo Instituto Nacional de Estudos e Pesquisas Nacionais (INEP), cujo cálculo é realizado por escola, por rede e para o próprio país. A partir desse índice, o MEC acredita 
ser possível fixar metas de desenvolvimento educacional de médio prazo para cada instância.

As questóes referentes ao regime de colaboração foram retomadas por ocasião da elaboração do PAR. Para viabilizar políticas efetivas de intervenção e transformação da realidade destas escolas, o MEC propôs um novo regime de colaboração com estados e municípios, sendo o PAR o instrumento jurídico para a concretização deste novo regime. Seu caráter é plurianual, devendo ser construído com a participação dos gestores e educadores locais com base em diagnóstico elaborado pela coletividade, baseado no Instrumento de Avaliação de Campo que permite a análise compartilhada do sistema educacional em quatro dimensóes: gestão educacional, formação de professores e dos profissionais de serviço e apoio escolar, práticas pedagógicas e avaliação e infraestrutura física e recursos pedagógicos. Para participar do PAR os municípios assinaram um termo de adesão, "Compromisso Todos pela Educação", conforme o estabelecido no Decreto nº 6.094/2007. O compromisso recebeu a adesão de todos os 26 estados e do Distrito Federal. Aderiram 98\% dos municípios brasileiros.

A proposta é que o PAR seja construído de forma a promover a participação ativa dos gestores e educadores locais, das famílias e da comunidade e, assim, resguardar a organicidade das açóes e outorgar autonomia ao ente municipal. No que se refere ao enfoque de planejamento, o PAR propóe-se a desenvolver um conjunto de programas articulados para dar organicidade às açóes e, desse modo, o PDE nacional se afastaria da proposta do planejamento por objetivos, conforme se estruturava no modelo PDE/escola, e se configuraria como uma "proposta sistêmica".

Para isso, os municípios assumem o compromisso de melhorar a qualidade do ensino ofertado. O IDEB é o indicador para a verificação do cumprimento de metas fixadas no termo de adesão ao Compromisso (BRASIL, 2007). De acordo com informaçóes coletadas no site do MEC, ${ }^{3}$ os 26 estados mais o Distrito Federal, além de 5,3 mil municípios, aderiram ao Plano de Metas do Compromisso Todos pela Educação. A proposta do MEC é que o Brasil, nos próximos quinze anos, alcance a nota seis no IDEB. A Educação Básica brasileira tem uma média aproximada de quatro pontos em uma escala que vai de zero a dez. 


\section{Considerações finais: pontuando algumas questões sobre o alcance do PAR}

Desde o seu lançamento, o PAR é submetido a debates acadêmicos em que se confrontam seus pontos frágeis e suas potencialidades com respeito aos objetivos propostos. Questiona-se, por exemplo, a dubiedade da concepção de sistema que subjaz à proposta de organicidade entre as açóes pelo fato de que, ao lançar o PDE, em 2007, o governo não procurou harmonizá-lo com o PNE. Ao contrário, este último passou a ocupar lugar secundário no planejamento de programas governamentais. Outra dúvida se refere à possibilidade de se consolidar o regime de colaboração, de proporcionar maior autonomia aos entes federados, enfim, de contribuir para a equalizaçáo da oferta educacional e para a sua qualidade sem a concretização de uma racionalidade administrativa democrática e emancipatória.

Sousa (2009) destaca que, para a implantação do PDE, o MEC passou por uma reestruturação na sua estrutura organizativa com a extinção e a criação de novas diretorias e coordenações gerais e com a redefinição da atuação das suas três principais autarquias vinculadas: o Fundo Nacional de Desenvolvimento da Educação (FNDE), o Instituto Nacional de Estudos e Pesquisas Educacionais Anísio Teixeira (INEP) e a Coordenação de Aperfeiçoamento de Pessoal de Nível Superior (CAPES). Esta última passou a ter entre suas atribuiçóes a formação de professores para a Educação Básica, sendo encarregada não apenas no que se refere à formulação das políticas e diretrizes, mas também no monitoramento e avaliação do plano. Fica claro, portanto, que distintos órgãos se responsabilizam pela regulação do processo, o que leva ao questionamento sobre a prática de articulação entre os órgãos na condução da árdua e complexa tarefa de acompanhamento do PAR em todo o país.

Quando se examina as bases conceituais do PDE surge outra questão referente ao modo operacional de conceber o "sistema educacional". Isto porque a multiplicidade de órgáos pode gerar heterogeneidade nos métodos e critérios para a consecução da assistência técnica aos municípios. No sentido que lhe dá Saviani $(2008$, p. 3), o termo sistema, para além do seu uso indiscriminado, denota a reunião de várias unidades formando um todo:

mas é preciso considerar que, para lá dessas acepçóes, o termo sistema denota um conjunto de atividades 
que se cumprem tendo em vista determinada finalidade. $\mathrm{E}$ isso implica que as referidas atividades são organizadas segundo normas decorrentes dos valores que estão na base da finalidade preconizada.

Diferentemente dessa visão orgânica, o enfoque sistêmico - no sentido funcionalista - considera que a finalidade das mudanças é prover soluções para os problemas que emperram o "funcionamento do sistema", entre outros, a evasão, a repetência, a distorção idade-série, o baixo rendimento escolar. Segundo esse enfoque, a simples correção desses problemas gera a melhoria do todo, visto que o sistema se garante pela interrelação harmônica entre elementos. A finalidade do sistema, aqui, limita-se ao sentido heurístico e, portanto, perde seu caráter de valor maior que deve sustentar um projeto nacional de educação. Em contraposição ao modelo heurístico, Nóvoa (1999) considera que os elementos-chave da dinâmica das mudanças organizacionais encontram-se no que ele chama de bases conceituais e pressupostos invisíveis da cultura organizacional das escolas. Esse conjunto de elementos deve interligar os valores, as crenças e as ideologias que os membros da organizaçáo partilham e que lhes permitem atribuir significados às açóes em prol de uma escola de qualidade.

Outro ponto de questionamento é a prática da descentralização exercida por meio do PAR. O MEC se propóe a fortalecer o regime de colaboração, comprometendo-se em ir ao encontro dos entes federados para conhecer a sua realidade e assumir o compromisso de assisti-los técnica e financeiramente na execução de seus projetos e açóes de melhoria da qualidade da educação. As experiências atuais vêm confirmando a tradicional dificuldade de equilíbrio entre as políticas locais e a central, sobretudo atualmente com as novas regulaçóes introduzidas pelas reformas educativas implantadas desde a década de 1990. Cada vez mais, atores sociais se multiplicam na formulação e execução das políticas locais, que contam com a presença da iniciativa privada e do terceiro setor. De acordo com análise de Oliveira (2007) sobre a emergência da categoria ação pública como explicativa das atuais tendências na gestão das políticas públicas sociais, a diversidade de situaçóes na implantação das políticas faz com que um mesmo programa social assuma características muito diferentes, dependendo do município que o executa, dadas as capacidades heterogêneas de gestão e implantação dos programas, principalmente os que implicam alto nível de 
investimento local. No caso do PAR, o investimento requerido não é somente financeiro, mas também de competência técnica e política dos atores locais.

Nesse caso, há que se perguntar até que ponto a ação do MEC primará pela descentralização responsável, isto é, se apoiará os municípios com ações efetivas de assistência técnica e financeira; de que forma se dará a colaboração; se manterá parcerias com Universidades e outras entidades científicas e representativas do campo educacional ou deixará os sistemas municipais executarem isoladamente as açóes do PAR, sem controle democrático e sem o cumprimento das finalidades pedagógicas. Uma análise preliminar dos dados coletados até o momento da pesquisa revela um distanciamento do MEC no sentido de assistir os sistemas com apoio técnico e financeiro.

Portanto, questóes concernentes ao processo de centralização/ descentralização na elaboração e execução do PAR são cruciais e devem ser analisadas. Enquanto no plano político-institucional os entes federativos são autônomos, no plano econômico, social e administrativo, o Brasil é estruturalmente um país marcado por profundas desigualdades. $\mathrm{O}$ país é constituído, na sua maioria, de municípios pequenos, com reduzida densidade demográfica, dependentes de transferências fiscais e sem tradição administrativa (ARRETCHE, 2000). Nesse contexto, a extensão da descentralização depende de que as políticas sejam executadas, de forma coordenada, nas esferas federal, estadual e municipal, a fim de apoiar fiscal e/ou administrativamente o poder local. Para alcançar pontos positivos e contíguos a descentralização pressupóe a existência de uma política de Estado.

Em geral, as ações descentralizadas se realizam nesse modelo de organização por meio de contratos entre o governo central e os governos subnacionais, as chamadas parcerias entre Uniāo, estados e municípios, outras instituições da sociedade civil e Organizaçóes Não Governamentais (ONG). Estudos sobre o papel do Estado (ARRETCHE, 2000; DINIZ, 2004; OLIVEIRA, 2004; 2007) esclarecem que a efetiva descentralização das políticas sociais no Brasil exige mudanças significativas na estrutura federativa e no papel do Estado, haja vista a expressiva desigualdade de natureza econômica, social, política que aflige os municípios.

A observação do fenômeno aqui estudado evidencia um elemento centralizador, visto que o PAR é um instrumento de aplicação de diagnósticos e de organização racional das açóes capazes de compensar a fragilidade operacional e política dos entes, o que justifica uma intervençáo planejada 
pelo centro. Formulado pelo governo nacional o planejamento pode implicar a execuçấo ritmada pelos interesses mais imediatos da União e com atendimento desigual aos municípios. Concorre para isto a própria diluiçáo da assistência técnica do MEC em diferentes órgáos executivos desarticulados.

No decorrer das entrevistas, os pesquisadores se depararam com a diferenciada capacidade administrativa e financeira dos governos locais. As equipes apresentaram dificuldades em prever as açóes futuras, o que constitui a base de um bom planejamento. Além disso, a participação dos segmentos da comunidade e da escola é reduzida devido à falta de informaçóes e/ou às injunçóes decorrentes das relaçóes de poder que inibem o posicionamento autônomo desses atores. Acresce um elemento centralizador no fenômeno estudado, visto que o PAR é um instrumento que prevê a aplicação de diagnóstico e de organização racional das açôes dentro de um cronograma pré-estabelecido pelo MEC. Corre-se, pois, o risco de que a execuçâo das açóes seja ritmada pelos interesses mais imediatos da União. Observa-se, também, a manutenção da prática de recepção, pelos sistemas, de programas dispersos e desconectados do PAR em virtude da própria dispersão do seu acompanhamento em diferentes órgãos sediados no MEC.

Ademais, o instrumento do PAR apresenta limitaçóes estruturais observadas na sua execução em alguns municípios participantes da amostra da pesquisa que dá suporte ao presente texto. Muitas equipes do sistema municipal de educação, convocadas para elaborar o PAR, apresentaram dificuldades em diagnosticar seus problemas, dando a perceber que a complexidade e a abrangência das questóes educacionais dispostas no instrumento dificultaram a identificação dos problemas. Ao mesmo tempo, as informaçóes sobre o PAR estavam centradas na figura do dirigente da Secretaria de Educaçáo e a equipe local somente tomava conhecimento das orientaçóes no momento de sua execução.

Portanto, a aplicação do PAR nos municípios trouxe uma nova estratégia de açáo até entấo náo vivenciada pela totalidade do sistema. Ao mesmo tempo, a exiguidade do tempo previsto pelo FNDE para o cumprimento das açóes provocou uma reação automática de "cumprimento de uma obrigação" sem a devida avaliação da capacidade de atendimento de cada sistema e das reais condiçôes de aplicabilidade do plano. Desse modo, a implantaçáo do PAR deu-se, em muitos casos, por improviso, sem levar 
em conta a debilidade das condiçóes locais. Pressionados pelo imediatismo da racionalidade técnica, os entes se viram limitados quanto à "efetiva autonomia decisória e executiva, indispensáveis à descentralização e a formas mais democráticas de gestão" (OLIVEIRA, 2007, p. 16).

Com base nos questionamentos aqui elencados, fica a constatação de que, embora o PAR apresente uma proposta para estimular a participação dos entes que detêm a responsabilidade pela sua execução, alguns cuidados devem ser observados na relação entre o MEC e os executores locais para o cumprimento efetivo da proposta. Deve-se reconhecer que a implantação do PAR em sua plenitude é uma meta difícil de ser consolidada no isolamento de uma unidade escolar. O que se almeja é o comprometimento da União em garantir efetivo regime de colaboração e o atendimento igualitário a todos os sistemas. Desse modo, cumpre-se o papel nuclear do Estado no sentido de colaborar para a superação das dificuldades orçamentárias, gestionárias e pedagógicas que afligem os entes administrativos locais.

\section{Notas}

1 Este texto deriva de estudos desenvolvidos no âmbito da pesquisa "Gestão das políticas educacionais no Brasil e seus mecanismos de centralização e descentralização: o desafio do Plano de Açóes Articuladas (PAR)". Trata-se de estudo exploratório, com uso de pesquisas bibliográficas e documentais, além de trabalho de campo que privilegia o diálogo entre pesquisador-interlocutor, com o recurso de entrevistas semiestruturadas e monitoramento das açóes do PAR em quatro municípios de cada ente federativo envolvido na amostra (Bahia, Espírito Santo, Maranhão e Minas Gerais). A pesquisa conta com financiamento da FAPES e do CNPq.

2 A pesquisa foi executada no período de 2002-2005, incluindo pesquisadores da Universidade de Goiás, Mato Grosso do Sul, Tocantins e Minas Gerais, tendo sido publicada sob o título "Escolas gerenciadas: planos de desenvolvimento e projetos político-pedagógicos em debate" (FONSECA; TOSCHI; OLIVEIRA, 2004).

3 Disponível em: <http://portal.mec.gov.br/> Acesso em: 24 abr. 2009. 


\section{REFERÊNCIAS}

ARRETCHE, M. Estado federativo e politicas sociais: determinantes da descentralização. São Paulo: Fapesp, 2000.

BAIA HORTA, J. S. Liberalismo, tecnocracia e planejamento educacional no Brasil. São Paulo: Cortez, 1982.

BOBBIO. N. O futuro da democracia: uma defesa das regras do jogo. Rio de Janeiro: Paz e Terra, 1986.

BRASIL. Ministério da Administração e Reforma do Estado. Plano Diretor da Reforma do Estado. Brasília, DF: MARE, 1995.

BRASIL. Constituição (1988). Constituição da República Federativa do Brasil, Brasília, DF: Senado, 1988.

BRASIL. Ministério da Educação. III Plano Setorial de Educação e Cultura: 1980-1985. Brasília, DF: MEC, 1980.

BRASIL. Ministério da Educação. O Plano de Desenvolvimento da Educação: razões, princípios e programas. Brasília, DF: MEC, 2007. BRASIL. Ministério da Educação. Plano Decenal de Educação para Todos. Brasília, DF: MEC, 1993.

BRASIL. Ministério da Educação. Plano de Ações Articuladas. Brasília, DF: MEC, 2007.

BRASIL. Instituto Nacional de Estudos e Pesquisas Educacionais Anísio Teixeira. Índice de Desenvolvimento da Educação. Brasília, DF: INEP, 2007.

BRASIL. Ministério da Educação. Plano Nacional de Educação. Brasília, DF: MEC, 1962.

BRASIL. Lei no 11.494, de 20 de junho de 2007. Regulamenta o Fundo de Manutenção e Desenvolvimento da Educação Básica e de Valorização dos Profissionais da Educação (FUNDEB), de que trata o art. 60 do Ato das Disposiçôes Constitucionais Transitórias; altera a Lei no 10.195 , de 14 de fevereiro de 2001; revoga dispositivos das Leis $\mathrm{n}^{\mathrm{os}}$ 9.424, de 24 de dezembro de 1996, 10.880, de 9 de junho de 2004, e 10.845, de 5 de março de 2004; e dá outras providências. Brasília, DF: Senado, 2007. 
BRASIL. Lei no 10.172, de 9 de janeiro de 2001. Institui o Plano Nacional de Educação e dá outras providências. Diário Oficial da União, Brasília, DF, 10 jan. 2001.

BRASIL. Lei no 4.024, de 20 de dezembro de 1961. Fixa as diretrizes e bases da educação nacional. Diário Oficial da Uniáo. Disponível em: <http://www.planalto.gov.br/ccivil_03/leis/14024.htm>. Acesso em: 10 jan. 2011.

BRASIL. Lei no 5.692, de 11 de agosto de 1971. Fixa diretrizes e bases para o ensino de $1^{\circ}$ e $2^{\circ}$ graus e dá outras providências. Disponível em http:// www.planalto.gov.br/ccivil_03/leis/15692.htm. Acesso em: 15 jan. 2011.

BRASIL. Ministério da Educação. Plano Setorial de Educação e Cultura: 1986-1989. Brasília, DF: MEC, 1986.

BRASIL. Decreto no 6.094, de 24 de abril de 2007. Dispóe sobre a implementação do Plano de Metas Compromisso Todos pela Educação, pela União Federal, em regime de colaboração com Municípios, Distrito Federal e Estados, e a participação das famílias e da comunidade, mediante programas e ações de assistência técnica e financeira, visando a mobilização social pela melhoria da qualidade da educação básica. Diário Oficial da União, Brasília, DF, 24 abr. 2007.

BRASIL. Ministério da Educação. Plano Trienal de Educação. Brasília, DF: MEC, 1963.

BRESSER PEREIRA, L.C. Estado e subdesenvolvimento industrializado. 2. ed. São Paulo: Brasiliense, 1977.

BRUNO, L. Reestruturação capitalista e Estado Nacional. In: Oliveira, D. A.; Duarte, M. R. T. (Org.). Politica e trabalho na escola. Belo Horizonte: Autêntica, 1999. p. 13-41.

CAMINI, L. A relação do MEC com os entes federados na implantação do PDE/ Plano de Metas Compromisso de Todos pela Educação: tensões e tendências. Disponível em: <http://www gt5.ufpr.br>. Acesso em: 10 ago. 2010. CRUZ, R. E. Federalismo e financiamento da educação: a política do FNDE em debate. Disponível em: <http://www gt5.ufpr.br> Acesso em: 10 ago. 2010). 
Declaração Mundial sobre Educação para Todos. Nova York, UNICEF, 1990. DINIZ, E. Globalizaçâo, reformas econômicas e elites empresariais. 2. ed. Rio de Janeiro: Ed. FGV, 2004.

FARENZENA, N. Políticas de assistência financeira da União no marco das responsabilidades (inter) governamentais em educaçâo básica. Disponível em: <http://www gt5.ufpr.br>. Acesso em: 10 ago. 2010.

FERREIRA, E. B. O planejamento da gestão da educação profissional sob uma nova lógica de regulação social. Revista de Ciência e Tecnologia, Vitória, 2007.

FONSECA, M. Políticas públicas para a qualidade da educação brasileira: entre o pragmatismo econômico e a responsabilidade social. Cadernos Cedes, Campinas, v. 29, n. 78, p. 153-177, maio/ago. 2009.

FONSECA, M; TOSCHI, M. S.; OLIVEIRA, J. F. Educação, gestão e organização escolar: concepçóes e tendências atuais. In: FONSECA, M; OLIVEIRA, J. F.; TOSCHI, M. S. (Org.). Escolas gerenciadas: planos de desenvolvimento e projetos político-pedagógicos em debate. Goiânia: Ed. da UCG, 2004.

IANNI, O. Estado e planejamento econômico no Brasil. 5. ed. Rio de Janeiro: Civilização Brasileira, 1995.

MARTINS, P. S. O financiamento da educação básica por meio de fundos contábeis: estratégia política para a eqüidade, a autonomia e o regime de colaboração entre os entes federados. 2009. 337 f. Tese (Doutorado em Educação) - Programa de Pós-Graduação em Educação, Universidade de Brasília, Brasília, DF, 2009.

MARTINS, P. S. Planejamento e Plano Nacional de Educação. Brasília: Consultoria Legislativa da Câmara dos Deputados, 2010.

NÓVOA, A. (Org.). As organizaçóes escolares em análise. 3. ed. Lisboa: Dom Quixote, 1999.

OLIVEIRA, D. A. A reestruturação do trabalho docente: precarização e flexibilização. Educação e Sociedade, São Paulo, v. 25, p. 1127-1144, set./ dez. 2004. 
OLIVEIRA, D. A. Regulação e avaliação de políticas públicas educacionais. In: DOURADO, L. (Org.). Políticas e gestão: novos marcos regulatórios da educação no Brasil. São Paulo: Xamã, 2007.

PEREIRA, L. Ensaios de sociologia do desenvolvimento. 3. ed. São Paulo: Pioneira, 1978.

SARTORI, G. A teoria da democracia revisitada: as questōes clássicas. São Paulo: Ática, 1994.

SAVIANI, D. Sistema nacional de educação: conceito, papel histórico e obstáculos para sua construção no Brasil. In: REUNIÃO ANUAL DA ASSOCIAÇÃO NACIONAL DE PÓS-GRADUAÇÃO E PESQUISA EM EDUCAÇÃO, 31, 2008, Caxambu. Anais eletrônicos... Caxambu, 2008. Disponível em: <http://www.anped. org.br/reunioes/31ra/5trabalhos_encomendados/trabalho $\% 20$ encomendado\%20-\%20gt05\%20-\%20dermeval\%20saviani.pdf>. Acesso em: 18 jan. 2011. Texto apresentado no GT-05: Estado e Política Educacional.

SCAFF, E. A. da S. Planejamento da educação e cooperação internacional: uma análise dos programas Monhangara e Fundescola. 2007. 255 f. Tese (Doutorado em Educação) - Programa de Pós-Graduação em Educação, Universidade de São Paulo, São Paulo, 2007.

SOUSA, B. J. R. Os planos e a gestão da educação básica no Brasil: o PDE em análise. In: SIMPÓSIO BRASILEIRO DE POLÍTICA E ADMINISTRAÇÃO DA EDUCAÇÃO, 24; CONGRESSO INTERAMERICANO DE POLÍTICA E ADMINISTRAÇÃO, 3., 2009, Vitória. Anais eletrônicos... Vitória, 2010. Disponível em: <http:// www.anpae.org.br/congressos_antigos/simposio2009/49.pdf>. Acesso em: 10 ago. 2010. 


\section{Management of the educative policies in Brazil and their current challenges}

\section{Abstract}

The present text presents preliminary reflections coming from inter institutional research focused on the Articulated Action Plan (PAR). To do so, a historical and political approach about the planning in Brazil is made standing out the educative process and the polarization between the educators and technocrats perspectives. The presence of multilateral organisms in the planning of the Brazilian educative policies is stood out in the nineties and the emergency of the rational or managerial management observed in the reform project of the Brazilian State. It is understood that the public management has become more technical, offering rational solutions, supposedly neutral, in order to face the social and economical problems. With PAR, during Lula's government, it is inaugurated a way of systemic planning, through the adoption of a mechanism that establishes a collaboration regime among the federative beings. MEC proposes to strengthen the collaboration regime, compromising to meet with the federated beings to know their reality and to assume the commitment to give technical and financial assistance. This research evidences the traditional difficulty of balance between the local and central policies, especially nowadays with the

\section{La planificación de las políticas educativas en Brasil y sus rectos actuales}

\section{Resumen}

Este documento tiene como objetivo presentar reflexiones preliminares procedentes de una investigación interinstitucional centrada en el Plano de Acciones Articuladas - PAR. Los procedimientos metodológicos adoptados fueron los siguientes: análisis bibliográfico sobre la planificación en Brasil; análisis de los documentos legales y normativos de creación e implantación del PAR; entrevistas con los técnicos responsables por la planificación de los municipios participantes de la muestra. Con el PAR, el gobierno Lula inauguró una forma de planificación sistemática a través de la adopción de un mecanismo que establece un régimen de colaboración entre las entidades federativas. La propuesta del Ministerio de la Educación fue la de fortalecer el régimen de colaboración, con el compromiso de ir al encuentro de las entidades federativas para conocer su realidad y asumir el compromiso de asistirlos técnica y financieramente. Esta investigación demostró la tradicional dificultad de equilibrio entre las políticas locales y la central, sobre todo actualmente con las nuevas regulaciones introducidas por las reformas educativas implantadas desde la década de 1990. La gestión pública se ha vuelto más técnica, ofreciendo 
new regulations introduced by the soluciones racionales, supuestamente educative reforms implanted since neutras, para el enfrentamiento de 1990. los problemas económicos y sociales. Keywords: Educational planning. Además, las entrevistas revelaron las Centralization. Decentralization. dificultades de los equipos en prever las acciones futuras, lo que constituye la base de una buena planificación, agravada por la baja participación de los sectores de la comunidad y de la escuela debido a la falta de informaciones y/o determinaciones decurrentes de las relaciones de poder local que impiden el posicionamiento autónomo de los sujetos.

Palabras clave: Planificación de la educación. Centralización. Descentralización.

\section{Eliza Bartolozzi}

E-mail: eliza.bartolozzi@gmail.com

\section{Marília Fonseca}

E-mail: fmarilia@gmail.com

Recebido em: $2 / 10 / 2010$

Versáo final recebida em: $28 / 3 / 2011$

Aprovado em: 4/4/2011 